\title{
Kinetic Studies of the Reactions of Atomic Chlorine and Bromine with Sllane
}

\author{
Luying Ding and Paul Marshall* \\ Department of Chemistry, University of North Texas, PO Box 5068, Denton, Texas 76203
}

(Received: September 11, 1991; In Final Form: November 21, 1991)

\begin{abstract}
The kinetics of the reactions $\mathrm{Cl}\left({ }^{2} \mathrm{P}_{\mathrm{J}}\right)+\mathrm{SiH}_{4}(1)$ and $\mathrm{Br}\left({ }^{2} \mathrm{P}_{\mathrm{J}}\right)+\mathrm{SiH}_{4}(2)$ have been investigated by time-resolved atomic resonance fluorescence spectroscopy. Halogen atoms were generated by flash photolysis of $\mathrm{CCl}_{4}$ and $\mathrm{CH}_{2} \mathrm{Br}_{2}$. Experiments over $295-472 \mathrm{~K}$ yielded $k_{1}=(1.56 \pm 0.11) \times 10^{-10} \exp \left[(2.0 \pm 0.2) \mathrm{kJ} \mathrm{mol}^{-1} / R T\right] \mathrm{cm}^{3} \mathrm{~s}^{-1}$ and studies over $295-575 \mathrm{~K}$ yielded $k_{2}=(9.0 \pm 1.5) \times 10^{-11} \exp \left[(-17.0 \pm 0.6) \mathrm{kJ} \mathrm{mol}^{-1} / R T\right] \mathrm{cm}^{3} \mathrm{~s}^{-1} .95 \%$ confidence intervals are about $\pm 10 \%$ and $\pm 20 \%$, respectively. These expressions are in good agreement with most earlier measurements. An expression for $k_{-1}$ is also derived. Alternative interpretations of the negative activation energy for $k_{1}$, based on transition-state theory or formation of an intermediate adduct, are discussed.
\end{abstract}

\section{Introduction}

The reactions of halogen atoms with silane have been important in studies of the chemistry of silicon hydrides. The reaction

$$
\mathrm{Cl}+\mathrm{SiH}_{4} \rightarrow \mathrm{SiH}_{3}+\mathrm{HCl}
$$

has been used as a source of $\mathrm{SiH}_{3}$ radicals in kinetic experiments, ${ }^{1-6}$ while recent measurements of the forward and back rate constants for the process

$$
\mathrm{Br}+\mathrm{SiH}_{4} \rightarrow \mathrm{SiH}_{3}+\mathrm{HBr}
$$

have provided an important measurement of the $\mathrm{SiH}_{3}-\mathrm{H}$ bond energy. 6 That investigation was complicated by secondary reactions of $\mathrm{Br}$ which required modeling to derive $k_{2}$, and one aim of the present work is to measure $k_{2}$ under conditions where secondary chemistry is negligible, in order to provide a check of the previous $k_{2}$ determinations and thus $\Delta H_{\mathrm{f}}{ }^{\circ}\left(\mathrm{SiH}_{3}\right)$. A stable adduct has been proposed as an intermediate in reaction 2 and its iodine analogue. ${ }^{6}$ Here we have measured $k_{1}$ to see if such complexes might be important in reaction 1 also. This is significant because reaction 1 is much more amenable to quantitative molecular orbital analysis than reaction 2 .

\section{Experimental Technique}

Argon bath gas containing a halogenated methane, $\mathrm{CCl}_{4}$ for $\mathrm{Cl}$ and $\mathrm{CH}_{2} \mathrm{Br}_{2}$ for $\mathrm{Br}$, and $\mathrm{SiH}_{4}$ flows through the reactor. Halogen atoms are produced by pulsed photodissociation of the halogenated methane precursor by means of radiation from a flash lamp and are monitored by time-resolved atomic resonance fluorescence spectroscopy.

Reactor and Gas-Handling System. The reactor (Figure 1) consists of a six-way stainless steel cross. The intersection region of the side arms defines the reaction zone, where transient species are generated photolytically and detected by resonance fluorescence. Pulsed UV radiation enters the reactor through one port, resonance radiation through another at right angles, and fluorescence exists via a third mutually perpendicular sidearm. The other three sidearms are used as a gas inlet and outlet and as a port to hold a thermocouple. Temperature readings $T$ are corrected for radiation errors, which were determined in separate experiments with a shielded and unshielded thermocouple, and have an estimated uncertainty of $2 \% .^{7}$ Full details of the reactor and gas-handling system may be found elsewhere. ${ }^{8}$ An im-

(1) Krasnoperov, L. N.; Chesnokov, E. N.; Panfilov, V. N. Chem. Phys. 1984, 89, 297.

(2) Krasnoperov, L. N.; Chesnokov, E. N.; Panfilov, V. N. Dokl. Phys. Chem. 1984, 277,636.

(3) Chasovnikov, S. A.; Krasnoperov, L. N. Khim. Fiz. 1987, 6, 956. (4) Slagle, I. R.; Bernhardt, J. R.; Gutman, D. Chem. Phys. Lett. 1988, 149,180 .

(5) Sugawara, K.; Nakanaga, T: Takeo, H : Matsumura, C. Chem. Phys. Lett. 1989, 157, 309

(6) Seetula, J. A.; Feng, Y.; Gutman, D.; Seakins, P. W.; Pilling, M. J. J. Phys. Chem. 1991, 95, 1658

(7) Ding, L.; Shi, Y.; Marshall, P., to be submitted. provement over that earlier design ${ }^{8}$ is that a small fraction of the total Ar flow, about $10 \%$, is introduced in front of the three optical ports to sweep the gas mixture away from the windows.

Optical System. Radiation for pulsed photolysis of the halogenated methanes is provided by an EG\&G Electro-Optics flash lamp system. It consists of a bulb (special FX 193 with a $\mathrm{MgF}_{2}$ window) plugged into a Lite-Pac (FY-714) and connected to a power supply (PS-302) with a 10- $\mu \mathrm{F}$ external capacitor (CSI, 4 W508TN). According to the flash lamp manufacturer, the width of the output pulse at one-third peak height should be approximately $7 \mu \mathrm{s}$. The energy is controlled between 1.25 and $5 \mathrm{~J}$ by adjusting the output voltage of the power supply between 500 and $1000 \mathrm{~V}$. A MgF 2 plano-convex lens (75- $\mathrm{mm}$ focal length, 25.4-mm diameter) is mounted at the end of one arm of the reactor so that the flash lamp beam is partially focused through it into the reaction zone. The region between the flash lamp and the lens is purged with $\mathrm{N}_{2}$ (Linde, dry grade) to allow transmission of actinic radiation with wavelengths down to about $120 \mathrm{~nm}$ into the reactor. Flashes were repeated at $1-2 \mathrm{~Hz}$, which is slower than the replenishment rate of gas in the reaction zone, ${ }^{9}$ which in turn is slower than the time scale of the kinetics. Thus the measurements are carried out under pseudostatic conditions.

Resonance radiation is generated by a microwave-powered discharge lamp. $\mathrm{A} \mathrm{MgF}$, plano-convex lens (100-mm focal length, 25.4-mm diameter) is cemented to the lamp body to focus the radiation beam partially. The lamp is attached to the end of a sidearm of the reactor by means of an O-ring fitting. A tuned Evenson cavity is installed around the lamp and powered by a microwave generator (Opthos Instruments, Inc., $2540 \mathrm{MHz}$ ). For $\mathrm{Cl}$ resonance radiation, $(4 \mathrm{~s})^{2} \mathrm{P} \rightarrow(4 \mathrm{p})^{2} \mathrm{P}_{1 / 2,3 / 2},(\lambda=134-140$ $\mathrm{nm}),{ }^{10}$ a dilution of $0.1 \%$ of $\mathrm{CCl}_{4}$ in Ar flows continuously through the lamp and is removed with a rotary pump (Welch Model 1399). The discharge is initiated with a Tesla coil. A typical microwave power is $20 \mathrm{~W}$, and the lamp is cooled by a jet of air. The $\mathrm{CCl}_{4}$ mixture is prepared by diluting pure $\mathrm{CCl}_{4}$ vapor (J.T. Baker, $99 \%$ ) with $\operatorname{Ar}$ (Linde, $99.996 \%$ ) and stored in a 5-L reservoir bulb. The gas flow rate is controlled by a needle valve, adjusted to keep the lamp pressure at $30 \mathrm{~Pa}$ as measured by a thermocouple gauge (Edwards, 507). For $\mathrm{Br}$ radiation, $(5 \mathrm{~s})^{2} \mathrm{P},{ }^{4} \mathrm{P} \rightarrow(4 \mathrm{p})^{2} \mathrm{P}_{1 / 2,3 / 2}(\lambda$ $=149-163 \mathrm{~nm}$ ), ${ }^{10}$ a $0.1 \%$ mixture of $\mathrm{CH}_{2} \mathrm{Br}_{2}$ (Eastman Organic Chemicals) is employed in the flow lamp instead. Ar is used as supplied while $\mathrm{CCl}_{4}$ and $\mathrm{CH}_{2} \mathrm{Br}_{2}$ are purified by three freezepump-thaw cycles.

A solar-blind UV photomultiplier tube (Thorn EMI, 9423B) monitors the emitted light intensity from the reaction zone. The PMT is operated at $3 \mathrm{kV}$, generated by a Bertan Model 215 power

(8) Shi, Y.; Marshall, P. J. Phys. Chem. 1991, 95, 1654.

(9) In ref 8 the average residence time of gas in the reactor before photolysis is characterized as $\tau_{\text {res. }}$. The average residence time in the smaller reaction zone itself is estimated to be about $0.1 \tau_{\text {res }}$ 1978 . 


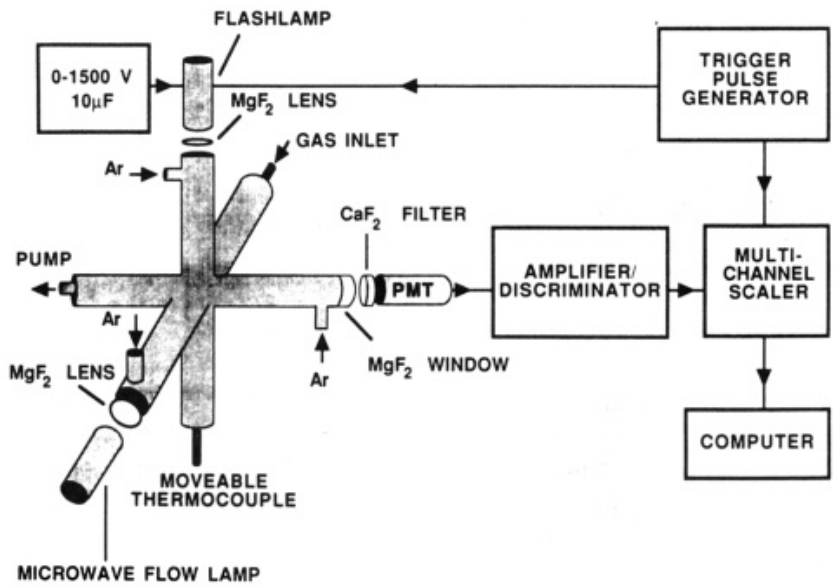

Figure 1. Schematic diagram of the apparatus.

supply. Fluorescence exits the reactor through a $\mathrm{MgF}_{2}$ window which is glued to a brass holder attached at the end of one arm of the reactor (see Figure 1). The region between this window and the PMT is purged with $\mathrm{N}_{2}$ to prevent air absorbing the vacuum UV fluorescence.

A potential interference is detection of $\mathrm{H}$ atoms as well as the desired halogen atoms. To avoid this during measurements of $k_{2}$, a $\mathrm{CaF}_{2}$ filter was placed in front of the PMT to block any $\mathrm{H}$-atom fluorescence (see Figure 1). Preliminary tests indicated that no $\mathrm{H}$ atoms were detected after firing the flash lamp in the presence of $\mathrm{SiH}_{4}$ and $\mathrm{Ar}$ alone. Later it was found that no $\mathrm{H}$ atoms were detected even if the $\mathrm{CaF}_{2}$ filter was removed, and this modified arrangement was used in the determinations of $k_{1}$.

Electronics. A digital delay/pulse generator (Stanford Research Systems, DG 535) controls the timing of the experiments. It provides trigger pulses to the flash lamp and to a computercontrolled multichannel scaler (EG\&G Ortec ACE), which collects the resonance fluorescence signal from the PMT via a preamplifier/discriminator (MIT Model F-100T). This detection system counts the number of photons emitted as a function of time. Signals following typically 50-500 flashes are collected and summed to average out random noise. All data are stored and analyzed by an IBM XT-compatible microcomputer.

Data Analysis. The rate of removal of atomic halogen in the presence of $\mathrm{SiH}_{4}$ can be expressed, e.g., for $\mathrm{Cl}$ atoms, as

$$
-\mathrm{d}[\mathrm{Cl}] / \mathrm{d} t=k_{1}\left[\mathrm{SiH}_{4}\right][\mathrm{Cl}]+k_{\mathrm{diff}}[\mathrm{Cl}]
$$

where $k_{1}$ is the second-order rate constant for reaction 1 , and $k_{\text {diff }}$ accounts for the loss of $\mathrm{Cl}$ atoms by processes other than reaction 1 , primarily diffusion out of the reaction zone. Because $[\mathrm{Cl}] \ll$ $\left[\mathrm{SiH}_{4}\right]$, pseudo-first-order conditions apply, and eq 3 becomes

$$
-\mathrm{d}[\mathrm{Cl}] / \mathrm{d} t=k_{\mathrm{ps} 1}[\mathrm{Cl}]
$$

where the pseudo-first-order rate constant is given by

$$
k_{\mathrm{ps} 1}=k_{1}\left[\mathrm{SiH}_{4}\right]+k_{\text {diff }}
$$

The integrated form of eq 4 is the general first-order reaction result

$$
[\mathrm{Cl}]=[\mathrm{Cl}]_{0} \exp \left(-k_{\mathrm{ps} 1} t\right)
$$

where $t$ is the time after the photolysis pulse and $[\mathrm{Cl}]_{0}$ is the concentration of $\mathrm{Cl}$ atoms at $t=0$ in the experiment. The intensity of fluorescence is proportional to $[\mathrm{Cl}]$. There is also a steady background signal $B$, arising from scattered light from the resonance lamp, so that the total signal $I$ is represented by

$$
I=A \exp \left(-k_{\mathrm{ps} 1} t\right)+B
$$

where $A$ and $B$ are constants. A computer program using a weighted nonlinear least-squares method ${ }^{11}$ fits $A, B$, and $k_{\mathrm{ps} 1}$ to each fluorescence decay curve (see Figure 2). $k_{\mathrm{ps} 1}$ is measured

(11) (a) Marshall, P. Comput. Chem. 1987, 11, 219. (b) Marshall, P. Comput. Chem. 1989, 13, 103.

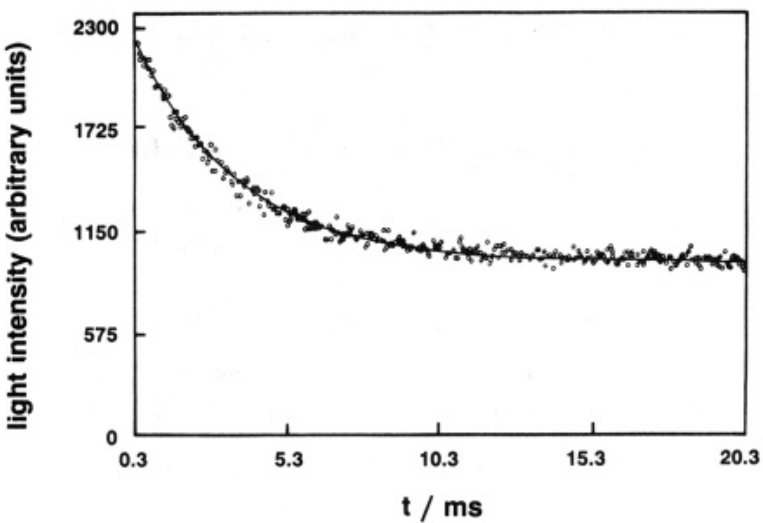

Figure 2. Plot of emitted light intensity vs time after photolysis, showing the fit to the form $A \exp \left(-k_{\mathrm{ps} 1} t\right)+B$, where $k_{\mathrm{ps} 1}$ is the pseudo-first-order rate constant for the reaction $\mathrm{Cl}+\mathrm{SiH}_{4}$ and $\mathrm{B}$ is the background from scattered light. $T=295 \mathrm{~K}, P=6.7 \mathrm{kPa},\left[\mathrm{CCl}_{4}\right]=9.0 \times 10^{14} \mathrm{~cm}^{-3}$, $\left[\mathrm{SiH}_{4}\right]=5.8 \times 10^{11} \mathrm{~cm}^{-3}$.

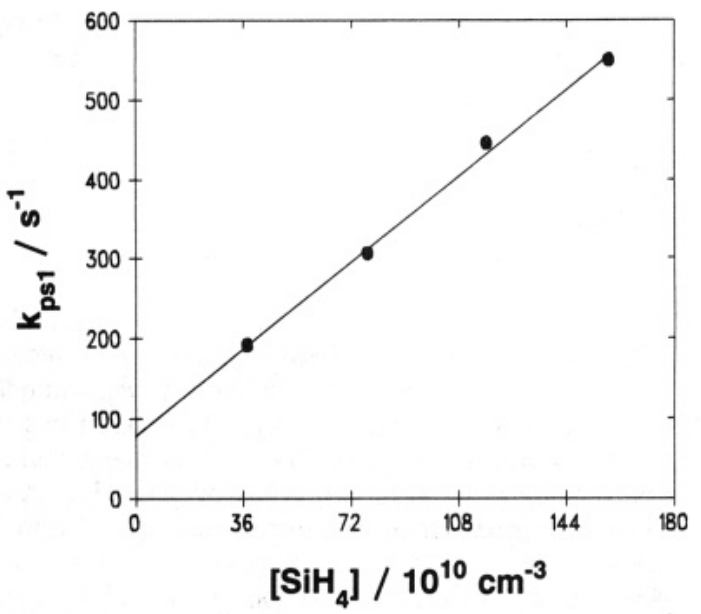

Figure 3. Plot of the pseudo-first-order rate constants for removal of $\mathrm{Cl}$ vs $\left[\mathrm{SiH}_{4}\right]$ at $T=323 \mathrm{~K}$ and $P=13.2 \mathrm{kPa}$.

for typically five values of $\left[\mathrm{SiH}_{4}\right]$, from 0 to $\left[\mathrm{SiH}_{4}\right]_{\max }$, at constant total number density $[\mathrm{M}] \approx[\mathrm{Ar}] . k_{1}$ is derived as the slope of a linear plot of $k_{\mathrm{ps} 1}$ versus [ $\mathrm{SiH}_{4}$ ] (see Figure 3), together with its standard deviation, $\sigma_{k 1}$, by weighted least-squares fitting. ${ }^{12}$ This $\sigma_{k 1}$ takes account of uncertainties in the derivation of individual $k_{\mathrm{ps} 1}$ values plus any changes in experimental parameters such as gas flow or temperature which might vary during a set of measurements at a particular temperature and pressure.

For reaction 1 only, the $k_{\mathrm{ps} 1}$ measurements with $\left[\mathrm{SiH}_{4}\right]=0$ were excluded from these fits because they were often higher than the intercepts of the fits through the other four points. The reason for this is unknown.

\section{Results}

$\mathbf{B r}+\mathbf{S i H}_{4}$. This reaction was used to make several checks on the correct operation of the apparatus and accordingly is discussed first. Twenty-seven measurements of $k_{2}$ were made at $T=$ $295-575 \mathrm{~K}$ and are summarized in Table I. The individual decays of $[\mathrm{Br}]$ exhibited exponential behavior, and comparison of pairs of $k_{2}$ measurements made under conditions identical except for the flash energy, $F$, shows that a doubling of $F$ led to insignificant changes in $k_{2}$, e.g., between 1 and $15 \%$ at room temperature. This means that secondary reactions of $\mathrm{Br}$ with photolysis or reaction products were unimportant (in particular the reverse of reaction 2 did not interfere), and that pseudo-first-order conditions, $[\mathrm{Br}]$ $\ll\left[\mathrm{SiH}_{4}\right]$, held. There is no consistent variation of $k_{2}$ with $\tau_{\text {res }}$, the residence time of gases in the reactor before photolysis. This shows (a) that the gases were well-mixed in the reactor and (b)

(12) Irvin, J. A.; Quickenden, T. I. J. Chem. Educ. 1983, 60, 711. 
TABLE I: Summary of Rate Constant Measurements for $\mathrm{Br}+\mathrm{SiH}_{4}$

\begin{tabular}{|c|c|c|c|c|c|c|c|}
\hline$T, \mathbf{K}$ & $P, \mathrm{kPa}$ & $\begin{array}{c}{[\mathrm{M}] \approx[\mathrm{Ar}]} \\
10^{17} \mathrm{~cm}^{-3}\end{array}$ & $\tau_{\text {ress }} \mathrm{s}$ & $F, \mathrm{~J}$ & $\begin{array}{l}{\left[\mathrm{CH}_{2} \mathrm{Br}_{2}\right],} \\
10^{14} \mathrm{~cm}^{-3} \\
\end{array}$ & $\begin{array}{l}{\left[\mathrm{SiH}_{4}\right]_{\text {max }}} \\
10^{14} \mathrm{~cm}^{-3}\end{array}$ & $k_{1} \pm \sigma_{k 1}, 10^{-14} \mathrm{~cm}^{3} \mathrm{~s}^{-1}$ \\
\hline 295 & 3.33 & 8.19 & 1.0 & 5.00 & 8.52 & 6.57 & $7.95 \pm 0.21$ \\
\hline 295 & 3.33 & 8.19 & 1.0 & 2.45 & 8.51 & 6.58 & $8.03 \pm 0.49$ \\
\hline 297 & 6.67 & 16.3 & 1.0 & 4.05 & 33.9 & 6.57 & $7.04 \pm 0.36$ \\
\hline 297 & 6.67 & 16.3 & 1.0 & 4.05 & 8.88 & 6.58 & $8.01 \pm 0.06$ \\
\hline 296 & 6.67 & 16.3 & 2.0 & 4.05 & 7.39 & 12.8 & $9.82 \pm 0.71$ \\
\hline 295 & 26.7 & 65.5 & 3.0 & 5.00 & 8.44 & 25.0 & $11.9 \pm 0.6$ \\
\hline 295 & 26.7 & 65.4 & 3.0 & 2.45 & 8.43 & 25.0 & $11.4 \pm 0.5$ \\
\hline 293 & 26.7 & 66.0 & 3.0 & 4.05 & 20.1 & 9.96 & $11.9 \pm 1.1$ \\
\hline 295 & 40.1 & 98.6 & 3.0 & 5.00 & 3.56 & 14.9 & $7.60 \pm 0.37$ \\
\hline 295 & 40.1 & 98.6 & 3.0 & 2.45 & 3.56 & 14.9 & $6.69 \pm 0.51$ \\
\hline 333 & 6.67 & 14.5 & 1.0 & 5.00 & 7.46 & 6.53 & $19.3 \pm 0.7$ \\
\hline 333 & 6.67 & 14.5 & 1.0 & 4.05 & 7.46 & 6.53 & $20.0 \pm 0.9$ \\
\hline 333 & 6.67 & 14.5 & 1.0 & 2.45 & 7.46 & 6.53 & $18.1 \pm 0.8$ \\
\hline 378 & 3.33 & 6.39 & 1.0 & 4.05 & 6.92 & 3.19 & $48.7 \pm 1.1$ \\
\hline 378 & 6.67 & 12.8 & 1,0 & 4.05 & 7.00 & 3.19 & $48.0 \pm 0.8$ \\
\hline 420 & 6.67 & 11.5 & 0.5 & 4.05 & 3.30 & 1.51 & $56.6 \pm 1.0$ \\
\hline 422 & 6.73 & 11.6 & 1.0 & 4.05 & 6.50 & 1.45 & $67.0 \pm 1.0$ \\
\hline 472 & 6.67 & 10.2 & 1.0 & 4.05 & 5.51 & 0.71 & $143 \pm 1$ \\
\hline 472 & 6.80 & 10.4 & 2.0 & 4.05 & 6.79 & 1.42 & $130 \pm 5$ \\
\hline 526 & 6.67 & 9.19 & 0.5 & 4.05 & 4.84 & 0.64 & $221 \pm 3$ \\
\hline 529 & 6.73 & 9.23 & 1.5 & 4.05 & 5.02 & 0.94 & $217 \pm 4$ \\
\hline 566 & 3.33 & 4.27 & 1.0 & 4.05 & 4.25 & 0.60 & $168 \pm 6$ \\
\hline 565 & 6.67 & 8.54 & 2.0 & 4.05 & 4.47 & 0.57 & $134 \pm 9$ \\
\hline 569 & 6.67 & 8.48 & 0.5 & 4.05 & 4.27 & 0.48 & $280 \pm 8$ \\
\hline 570 & 6.67 & 8.47 & 1.0 & 4.05 & 4.44 & 0.62 & $306 \pm 3$ \\
\hline 575 & 3.33 & 4.20 & 0.5 & 4.05 & 2.21 & 0.31 & $252 \pm 30$ \\
\hline 575 & 6.67 & 8.40 & 1.0 & 4.05 & 4.41 & 0.30 & $259 \pm 10$ \\
\hline
\end{tabular}

TABLE II: Summary of Rate Constant Measurements for $\mathrm{Cl}+\mathrm{SIH}_{4}$

\begin{tabular}{cccccccc}
\hline$T, \mathrm{~K}$ & $P, \mathrm{kPa}$ & $\begin{array}{c}{[\mathrm{M}] \approx[\mathrm{Ar}],} \\
10^{18} \mathrm{~cm}^{-3}\end{array}$ & $\tau_{\text {res, }, \mathrm{s}}$ & $F, \mathrm{~J}$ & $\begin{array}{c}{\left[\mathrm{CCl}_{4}\right],} \\
10^{14} \mathrm{~cm}^{-3}\end{array}$ & $\begin{array}{c}{\left[\mathrm{SiH}_{4}\right]_{\max ,}} \\
10^{11} \mathrm{~cm}^{-3}\end{array} k_{1} \pm \sigma_{\mathrm{kl}}, 10^{-10} \mathrm{~cm}^{3} \mathrm{~s}^{-1}$ \\
\hline 295 & 6.69 & 1.64 & 1.0 & 4.05 & 8.97 & 7.76 & $3.50 \pm 0.08$ \\
296 & 6.69 & 1.64 & 1.0 & 5.00 & 8.98 & 5.80 & $3.45 \pm 0.32$ \\
296 & 6.69 & 1.64 & 1.0 & 2.45 & 8.98 & 5.81 & $3.58 \pm 0.49$ \\
323 & 13.2 & 2.96 & 2.0 & 4.05 & 9.10 & 15.8 & $3.06 \pm 0.11$ \\
343 & 6.73 & 1.42 & 2.0 & 4.05 & 9.27 & 11.7 & $3.14 \pm 0.16$ \\
375 & 13.2 & 2.56 & 1.0 & 4.05 & 8.03 & 7.90 & $3.06 \pm 0.05$ \\
414 & 6.71 & 1.17 & 1.0 & 4.05 & 7.23 & 6.00 & $2.68 \pm 0.16$ \\
472 & 6.72 & 1.03 & 1.0 & 4.05 & 6.35 & 5.96 & $2.78 \pm 0.13$ \\
472 & 6.67 & 1.02 & 2.0 & 4.05 & 7.41 & 7.75 & $2.54 \pm 0.04$
\end{tabular}

that no significant decomposition of $\mathrm{SiH}_{4}$ occurred. There is aiso no consistent dependence of $k_{2}$ on [M]

The Arrhenius plot (Figure 4) shows scatter that arises partly from factors reflected in the $\sigma_{k 2}$ values and partly from variations in experimental parameters which occurred between runs at different conditions. A linear fit to the Arrhenius form $k=A$ $\exp \left(-E_{\mathrm{a}} / R T\right)$, weighted to reflect both $\sigma_{k 2}$ and $\sigma_{T}{ }^{12}$ yields the following expression for $k_{2}$ :

\section{$k_{2}=$}

$$
(9.0 \pm 1.5) \times 10^{-11} \exp \left[(-17.0 \pm 0.6) \mathrm{kJ} \mathrm{mol}^{-1} / R T\right] \mathrm{cm}^{3} \mathrm{~s}^{-1}
$$

Errors in $A$ and $E_{\mathrm{a}}$ are $\pm 1 \sigma$. Because the errors of the Arrhenius parameters are correlated, the covariance of $A$ and $E_{\mathrm{a}}$ is taken into account when we estimate the uncertainties of the fitted $k_{2}{ }^{13}$ The statistical error in $k_{2}$ is $\sigma / k_{2}=5-9 \%$. The measurements may be influenced by errors that were constant over the course of the experiments and therefore do not contribute to the scatter of Figure 4. An allowance of $\pm 5 \%$ for these systematic errors yields the $95 \%$ confidence interval for $k_{2}$ as about $\pm 20 \%$.

$\mathbf{C l}+\mathbf{S i H}_{4}$. Nine measurements of $k_{1}$ were made at $T=$ $295-472 \mathrm{~K}$ and are summarized in Table II. Fewer measurements were made than for $k_{2}$ because good mixing and a lack of decomposition of $\mathrm{SiH}_{4}$ had already been demonstrated. At room temperature, $k_{1}$ changed by less than $4 \%$ when $F$ was doubled, which meant that secondary reactions of $\mathrm{Cl}$ with photolytic or reaction products were negligible, and therefore a single $F$ was 171 .

(13) Hëberger, K.; Kemēny, S.; Vidốczy, T. Int. J. Chem. Kinet. 1987, 19,

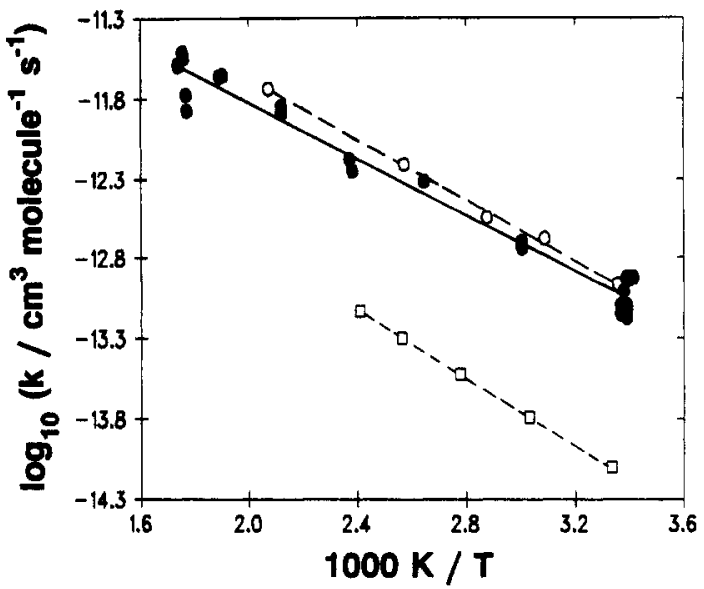

Figure 4. Arrhenius plot for the reaction $\mathrm{Br}+\mathrm{SiH}_{4}$ : (๑) present work; (O) Seetula et al., ${ }^{6}$ (D) Serdyuk et al. (see text). ${ }^{19}$

chosen for the rest of the measurements. $k_{1}$ was found to be independent of $\tau_{\text {res }}$ and $[\mathrm{M}]$.

Figure 5 shows the Arrhenius plot of $k_{1}$. A linear fit yields $k_{1}=$

$(1.56 \pm 0.11) \times 10^{-10} \exp \left[(2.0 \pm 0.2) \mathrm{kJ} \mathrm{mol}^{-1} / R T\right] \mathrm{cm}^{3} \mathrm{~s}^{-1}$

Consideration of the $1 \sigma$ errors in $A$ and $E_{\mathrm{a}}$, together with the covariance, leads to an estimated statistical error in $k_{1}$ of $\sigma / k_{1}$ $=2-3 \%$. Allowing for possible systematic errors of $\pm 5 \%$, the $95 \%$ confidence interval of $k_{1}$ is estimated at about $\pm 10 \%$. 


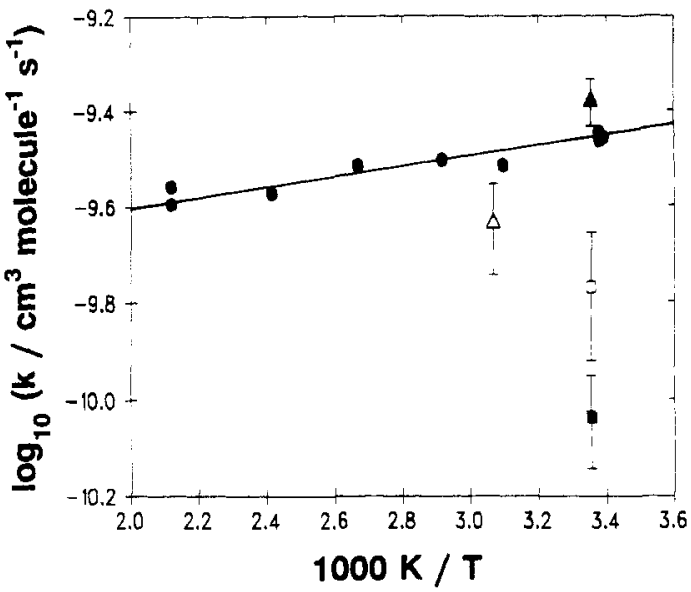

Figure 5. Arrhenius plot for the reaction $\mathrm{Cl}+\mathrm{SiH}_{4}$ : $(\bullet)$ present work; $(\Delta)$ Krasnoperov et al.,1,2 (ם) Chesnokov et al.; ${ }^{15}(\Delta)$ Niki et al., ${ }^{16}(\mathbb{\square})$ Shlyer et al. ${ }^{\text {? }}$

\section{Discussion}

Equilibrium of Halogen Atoms. For atomic $\mathrm{Cl}$ and $\mathrm{Br}$ the electronic ground state is ${ }^{2} \mathrm{P}_{3 / 2}$ and there is a low-lying excited ${ }^{2} \mathrm{P}_{1 / 2}$ state. For $\mathrm{Cl}$, the ${ }^{2} \mathrm{P}_{1 / 2}$ state lies $10.5 \mathrm{~kJ} \mathrm{~mol}^{-1}$ above the ground state and for $\mathrm{Br}$, the excitation energy is $44.0 \mathrm{~kJ} \mathrm{~mol}^{-1} .10$ Therefore, e.g., for atomic $\mathrm{Br}$, the following kinetic processes must be considered:

products $\stackrel{k_{\mathrm{C}}}{\longrightarrow} \operatorname{Br}\left({ }^{2} \mathrm{P}_{3 / 2}\right) \stackrel{k_{\mathrm{A}}}{\underset{k_{\mathrm{B}}}{\longrightarrow}} \operatorname{Br}\left({ }^{2} \mathrm{P}_{1 / 2}\right) \stackrel{k_{\mathrm{D}}}{\longrightarrow}$ products

$k_{\mathrm{B}}$ represents the pseudo-first-order quenching rate constant of $\mathrm{Br}\left({ }^{2} \mathrm{P}_{1 / 2}\right)$ and is linked to the excitation rate constant $k_{\mathrm{A}}$ via the statistical mechanical equilibrium constant $K_{\text {eq }}$ :

$$
k_{\mathrm{A}} / k_{\mathrm{B}}=K_{\mathrm{eq}}=e^{-\epsilon / k T} / 2
$$

where $\epsilon$ is the excitation of the ${ }^{2} \mathrm{P}_{1 / 2}$ state. $k_{\mathrm{C}}$ and $k_{\mathrm{D}}$ represent the state-specific pseudo-first-order rate constants for removal of $\operatorname{Br}\left({ }^{2} \mathrm{P}_{3 / 2}\right)$ and $\operatorname{Br}\left({ }^{2} \mathrm{P}_{1 / 2}\right)$ by chemical reactions.

Under conditions where $k_{\mathrm{A}}$ and $k_{\mathrm{B}} \gg k_{\mathrm{C}}$ and $k_{\mathrm{D}}$, i.e., where rapid equilibration of the two states is maintained, $\mathrm{Br}\left({ }^{2} \mathrm{P}_{3 / 2}\right)$ and $\mathrm{Br}\left({ }^{2} \mathrm{P}_{1 / 2}\right)$ form a kinetically coupled system and both exhibit the same pseudo-first-order decay coefficient of

$$
k_{\mathrm{ps} 1}=\left(k_{\mathrm{C}}+k_{\mathrm{D}} K_{\mathrm{eq}}\right) /\left(1+K_{\mathrm{eq}}\right)
$$

For our $\mathrm{Cl}$ experiments $\left[\mathrm{CCl}_{4}\right] \geq 6.4 \times 10^{14} \mathrm{~cm}^{-3}$ and $k_{\mathrm{O}}$, for $\mathrm{CCl}_{4}$, is $5 \times 10^{-11} \mathrm{~cm}^{3} \mathrm{~s}^{-1}$. ${ }^{14}$ So $k_{\mathrm{B}} \approx k_{\mathrm{Q}, \mathrm{CCl}_{4}}\left[\mathrm{CCl}_{4}\right]>3 \times 10^{4}$ $\mathrm{s}^{-1}$, which is much greater than $k_{\mathrm{ps} 1}$, which itself is up to $600 \mathrm{~s}^{-1}$. For the $\mathrm{Br}$ experiments, $k_{\mathrm{Q}}$ for $\mathrm{CH}_{2} \mathrm{Br}_{2}$ has not been measured. It presumably is at least as large as $k_{\mathrm{O}}$ for $\mathrm{CH}_{4}$ and $\mathrm{HBr},{ }^{14}$ i.e., $k_{\mathrm{Q}}>4 \times 10^{-12} \mathrm{~cm}^{-3} \mathrm{~s}^{-1}$. The $\left[\mathrm{CH}_{2} \mathrm{Br}_{2}\right]$ employed is in the range $(2-34) \times 10^{14}$ molecules $\mathrm{cm}^{-3}$, so $k_{\mathrm{B}}$ is at least $800-13000 \mathrm{~s}^{-1}$. $\mathrm{SiH}_{4}$ may also act as an efficient quencher and contribute to maintaining equilibrium between the two states of atomic $\mathrm{Br}$.

Thus all our kinetic measurements yield overall rate constants for the Boltzmann-averaged distribution of ${ }^{2} \mathrm{P}_{\mathrm{J}}$ atoms at each temperature.

$\mathbf{C I}+\mathbf{S i H}_{4}$. Previous studies have focussed on $k_{1}$ close to room temperature and did not examine the temperature dependence. Figure 5 shows two measurements by Panfilov and co-workers, who employed IR chemiluminescence ${ }^{15}$ and laser magnetic resonance, ${ }^{1,2}$ The latter result is closer to ours. The rate constant obtained by Niki et al. ${ }^{16}$ for reaction 1 at room temperature is in excellent agreement with our value, but the earlier measurement by Shlyer et al. ${ }^{17}$ lies significantly below ours. Niki et al. suggested

(14) Donovan, R J Husain, D Chem Rev 1970, 70, 489

(15) Chesnokov, E. N.; Panfilov, V. N. Khim. Fiz. 1982, 10, 1349.

(16) Niki, H.; Maker, P. D.; Savage, C. M.; Breitenbach, L. P. J. Phys. Chem. 1985, 89, 1752 . 2633 that because Shlyer et al. used $\mathrm{Cl}_{2}$ as their source of atomic $\mathrm{Cl}$, $\mathrm{Cl}$ may be regenerated after the primary reaction 1 by the reaction of $\mathrm{SiH}_{3}$ with $\mathrm{Cl}_{2}$, which leads to underestimation of $k_{1}$.

Recent enthalpy and entropy results for $\mathrm{SiH}_{3}{ }^{6}$ were combined with literature data for $\mathrm{H}_{2}$ and $\mathrm{Si}^{18}$ to derive $\Delta G_{\mathrm{f}}{ }^{\circ}\left(\mathrm{SiH}_{3}\right)$ as a function of temperature, which was then combined with tabulated $\Delta G_{f}^{\circ}$ values ${ }^{18}$ for $\mathrm{Cl}, \mathrm{SiH}_{4}$, and $\mathrm{HCl}$ to calculate the equilibrium constant $K$ for reaction 1 , where $K=k_{1} / k_{-1}$. The derived expression for the rate constant of the reverse of reaction 1 over the range $298-450 \mathrm{~K}$ is

$$
k_{1}=2.4 \times 10^{-12} \exp \left(-45.0 \mathrm{~kJ} \mathrm{~mol}^{-1} / R T\right) \mathrm{cm}^{3} \mathrm{~s}^{-1}
$$

where the uncertainty in $\Delta H^{\circ}{ }_{\mathrm{f}, 298}\left(\mathrm{SiH}_{3}\right)$ of $^{6} \pm 3.4 \mathrm{~kJ} \mathrm{~mol}^{-1}$ leads to an uncertainty in $k_{-1}$ of approximately a factor of 3 . The preexponential factor predicted here is reasonable and lies between those measured for the reactions of $\mathrm{SiH}_{3}$ with $\mathrm{HBr}$ and $\mathrm{HI}{ }^{6}$

$\mathbf{B r}+\mathbf{S i H}_{4}$. The room temperature rate constant obtained by Niki et al. ${ }^{16}$ is identical with our determination. The $k_{2}$ measurements by Seetula et al. ${ }^{6}$ from 298 to $483 \mathrm{~K}$ are in good agreement with ours, especially at room temperature. The individual Arrhenius parameters agree within their quoted uncertainties, and the maximum deviation between the two $k_{2}$ expressions of a factor of 1.4 at $480 \mathrm{~K}$ is at the limit of the combined uncertainties. Our results therefore provide a valuable confirmation of the previous $k_{2}$ measurements but carried out under conditions where, unlike in that earlier work, ${ }^{6}[\mathrm{Br}]$ was sufficiently low that secondary processes were negligible.

Serdyuk et al. ${ }^{19}$ have presented state-specific $k_{2}$ expressions for $\operatorname{Br}\left({ }^{2} \mathrm{P}_{3 / 2}\right)$ and $\operatorname{Br}\left({ }^{2} \mathrm{P}_{1 / 2}\right)$ which we combined according to eq 12 and plotted on Figure 4. It may be seen that their results are significantly lower than ours. A difficulty with their experimental design is that on the time scale of the measurements the two states of atomic $\mathrm{Br}$ would be expected to form a kinetically coupled system as discussed above, and we therefore question the validity of their $k_{2}$ determination for $\operatorname{Br}\left({ }^{2} \mathrm{P}_{1 / 2}\right)$.

Mechanistic Interpretation. The negative temperature dependence for $k_{1}\left(E_{\mathrm{a}}=-2.0 \pm 0.2 \mathrm{~kJ} \mathrm{~mol}^{-1}\right)$ is consistent with this reaction proceeding via a bound intermediate. ${ }^{20}$ Shlyer et al. ${ }^{17}$ speculated about the possibility of such a mechanism but had no $E_{\mathrm{a}}$ information for comparison. A similar mechanism has been proposed for the reverse of reaction 2 and its iodine analogue, whose activation energies were measured to be $-0.7 \pm 1.2$ and $-2.0 \pm 1.4 \mathrm{~kJ} \mathrm{~mol}^{-1}$, respectively. ${ }^{6}$ It therefore appears possible that the $\mathrm{SiH}_{4}+\mathrm{X} \rightleftarrows \mathrm{HX}+\mathrm{SiH}_{3}$ reactions for $\mathrm{X}=\mathrm{Cl}, \mathrm{Br}$, and I all proceed via adducts, which cause the negative temperature dependences for the kinetics in the exothermic direction. We plan to test this idea by searching for possible $\mathrm{SiH}_{3} \cdot \mathrm{HCl}$ adducts by $\mathrm{ab}$ initio theoretical methods. More reliable levels of theory may be applied to the hypothetical $\mathrm{Cl}$ adduct than to the proposed $\mathrm{Br}$ and I adducts, because of the smaller number of electrons.

An alternative explanation of the slightly negative $E_{\mathrm{a}}$ for reaction 1 comes from consideration of transition-state theory (TST) and the temperature dependences of the partition functions $Q$ of the reactants and the TS and has been outlined by Fontijn and Zellner. ${ }^{20}$ If the temperature dependence of $Q_{\text {vib }}$ is neglected, which will be a good approximation at low temperatures where $Q_{\text {vib }} \approx 1$, then combination of the $Q$ for the nonlinear reactants and the TS leads to

$$
E_{\mathrm{a}}=E_{0}-R T / 2
$$

where $E_{0}$ is the energy of the TS above the reactants at $0 \mathrm{~K} . R T / 2$ is $1.6 \mathrm{~kJ} \mathrm{~mol}^{-1}$ at the midpoint of the temperatures studied here, and in the limit of $E_{0} \rightarrow 0$ a negative $E_{\mathrm{a}}$ close to that observed may be possible. However, any loose vibrations $\left(Q_{\text {vib }}>1\right)$ in the TS will increase $E_{\mathrm{a}}$ above the lower limit of eq 14. Resolution

(18) Chase, M. W., Jr.; Davies, C. A.; Downey, J. R., Jr.; Frurip, D. J.; McDonald, R. A.; Syverud, A. N. JANAF Thermochemical Tables, 3rd ed. J. Phys. Chem. Ref. Data 1985, 14 (Suppl. No. 1).

(19) Serdyuk, N. K.; Gutorov, V. V.; Panfilov, V. N. React. Kinet. Catal. Lett. $1981,16,393$.

(20) Fontijn, A.; Zeliner, R. In Reactions of Small Transient Species Fontijn, A., Clyne, M. A. A., Eds.; Academic: London, 1983; Chapter 1. 
between these alternative explanations may perhaps be obtained via $a b$ initio characterization of the potential energy surface.

\section{Conclusions}

Rate constants for the reactions of $\mathrm{Cl}\left({ }^{2} \mathrm{P}_{\mathrm{J}}\right)$ and $\operatorname{Br}\left({ }^{2} \mathrm{P}_{\mathrm{J}}\right)$ with $\mathrm{SiH}_{4}$ have been measured and their temperature dependences determined. The results are in good accord with other reliable determinations of $k_{1}$ and $k_{2}$. An estimate of the reverse rate constant $k_{-1}$ is also derived. $k_{1}$ shows a negative temperature dependence and thus the reactions $\mathrm{SiH}_{3}+\mathrm{HX} \rightleftharpoons \mathrm{SiH}_{4}+\mathrm{X}(\mathrm{X}$
$=\mathrm{Cl}, \mathrm{Br}, \mathrm{I})$ all exhibit negative activation energies for reaction in the exothermic direction. This is consistent both with the idea that the mechanism involves formation of an intermediate adduct, as proposed earlier for $k_{-2}$ and the analogous $\mathrm{SiH}_{3}+\mathrm{HI}$ reaction, and with an interpretation based on transition-state theory.

Acknowledgment. We thank Texas Instruments, Inc., the Robert A. Welch Foundation (Grant B-1174), and the UNT Organized Research Fund for their support and Prof. R.T. Conlin for providing a sample of $\mathrm{CH}_{2} \mathrm{Br}_{2}$.

\title{
Study of the Pressure Dependence of the $\mathrm{N}_{2} \mathrm{~B}^{3} \Pi_{g}-\mathrm{A}^{3} \Sigma_{u}{ }^{+}$Chemiluminescence from the $\mathbf{N}+\mathbf{N}_{3}$ Reaction
}

\author{
Edwin Quiñones ${ }^{\dagger}$ and Paul J. Dagdigian* \\ Department of Chemistry, The Johns Hopkins University, Baltimore, Maryland 21218 \\ (Received: September 24, 1991; In Final Form: November 18, 1991)
}

\begin{abstract}
The $N_{2} B^{3} \Pi_{B} \rightarrow A^{3} \Sigma_{u}{ }^{+}$chemiluminescence spectrum from the $N+N_{3}$ reaction has been recorded in a discharge-flow experiment. The steady-state vibrational distribution in the $\mathrm{B}^{3} \Pi_{\mathrm{g}}$ state was derived as a function of added argon gas in order to gauge the role of nonreactive collisions in altering the nascent state distribution. It is found that the $\mathrm{B}^{3} \Pi_{\mathrm{g}}$ vibrational state distribution becomes hotter as argon is added to the flow at total pressures of up to 2.0 Torr. This suggests that nonemitting excited states of $\mathrm{N}_{2}$, in addition to the strongly emitting $\mathrm{B}^{3} \Pi_{\mathrm{g}}$ state, are formed in the $\mathrm{N}+\mathrm{N}_{3}$ reaction and provide an energy reservoir for the emitting levels.
\end{abstract}

\section{Introduction}

Because of the small dissociation energy of the azide radical to yield the ground-state products $\mathrm{N}\left({ }^{4} \mathrm{~S}\right)+\mathrm{N}_{2}\left(\mathrm{X}^{1} \Sigma_{\mathrm{g}}{ }^{+}\right)$, reactions of this molecular radical with atomic reagents to yield a nitride compound are very exothermic. Indeed, taking a recent determination ${ }^{1}$ of $\Delta H_{\mathrm{f}}^{\circ}\left(\mathrm{N}_{3}\right)=469 \pm 21 \mathrm{~kJ} / \mathrm{mol}$, the $\mathrm{N}-\mathrm{N}_{2}$ dissociation energy is calculated to be approximately zero $[2 \pm 21 \mathrm{~kJ} / \mathrm{mol}]$. The stability of this species with respect to dissociation is conferred by the fact that this dissociation channel is spin-forbidden. Because of this extremely small reagent dissociation energy, products of reactions involving the azide radical can be formed with a very high level of internal electronic and/or rovibrational excitation.

There have been a number of studies of the chemiluminescence resulting from the reactions of $\mathrm{N}_{3}$ with several different atomic species, most notably the halogens. ${ }^{2-5}$ There have also been several investigations of the reaction of the azide radical with nitrogen atoms, ${ }^{6-9}$ as well as with several heavier members of this atomic group [i.e., phosphorus ${ }^{10}$ and arsenic ${ }^{11}$ ]. The $\mathrm{N}+\mathrm{N}_{3}$ reaction, in particular, is found to yield intense nitrogen first positive $\left[\mathrm{B}^{3} \Pi_{\mathrm{B}}\right.$ $\left.\rightarrow \mathrm{A}^{3} \Sigma_{\mathrm{u}}{ }^{+}\right]$emission in the visible and near-infrared regions:

$$
\begin{aligned}
\mathrm{N}\left({ }^{4} \mathrm{~S}^{0}\right)+\mathrm{N}_{3}\left(\bar{X}^{2} \Pi_{\mathrm{g}}\right) \rightarrow \mathrm{N}_{2}^{*}+\mathrm{N}_{2}\left(\mathrm{X}^{1} \Sigma_{\mathrm{g}}^{+}\right), \quad \Delta H_{0}{ }^{0}= \\
-939 \pm 21 \mathrm{~kJ} / \mathrm{mol}
\end{aligned}
$$

The yield of the excited $B^{3} \Pi_{g}$ state, while not firmly established, is nonetheless found to be a significant fraction of the total reaction pathway. ${ }^{7,9}$

The large exothermicity of reaction 1 allows production of a number of excited electronic states of one of the nitrogen molecular products; the other molecule must be formed in the ground $\mathrm{X}^{1} \Sigma_{\mathrm{g}}^{+}$ state. If spin conservation were to apply in reaction 1 , as we would expect from the low atomic number of nitrogen, then the electronically excited product would be produced in a triplet state. The energetically accessible triplet states of $\mathrm{N}_{2}$ include the $\mathrm{A}^{3} \Sigma_{\mathrm{u}}^{+}$, $B^{3} \Pi_{g}, W^{3} \Delta_{v}$, and $B^{\prime 3} \Sigma_{u}{ }^{-}$states. ${ }^{12}$ The observation of first positive

\footnotetext{
'Present address: Department of Chemistry, University of Puerto Rico,
} Rio Piedras, PR 00931. emission, mentioned above, of course verifies the production of the $B^{3} \Pi_{3}$ state. David and Coombe ${ }^{7}$ give an orbital correlation argument to provide a rationalization that this excited electronic state, along with the $\mathrm{W}^{3} \Delta_{\mathrm{u}}$ state, should be formed in reaction 1. With the exothermicity quoted above, population up to and including the vibrational level $v^{\prime}=12$ is possible in the $B^{3} \Pi_{g}$ state.

The experimental studies on reaction 1 do not directly exclude the possibility of production of the other allowed triplet states. The lowest state, $\mathrm{A}^{3} \Sigma_{u}^{+}$, can be detected either by spin-forbidden $\mathrm{A}^{3} \Sigma_{\mathrm{u}}^{+} \rightarrow \mathrm{X}^{1} \Sigma_{\mathrm{g}}{ }^{+}$Vegard-Kaplan band emission, or possibly by laser fluorescence excitation in the $\mathrm{B}^{3} \Pi_{\mathrm{g}}-\mathrm{A}^{3} \Sigma_{\mathrm{u}}{ }^{+}$band system. The former method is much less sensitive than the observation of spin-allowed chemiluminescent emission, while the latter requires detection of the laser-induced signal above an intense chemiluminescent background. An additional complication with the detection of nascent $\mathrm{N}_{2}\left(\mathrm{~A}^{3} \Sigma_{u}{ }^{+}\right)$product is that this species is, of course, also produced by radiative, and also collisional, cascade from $\mathrm{N}_{2}\left(\mathrm{~B}^{3} \Pi_{\mathrm{g}}\right)$ through the first positive band emission. The $B^{\prime 3} \Sigma_{4}-$ state is known to emit in the red to the $B^{3} \Pi_{8}$ state; ${ }^{12}$ however, the $\mathrm{B}^{\prime} \rightarrow \mathrm{B}$ bands are not seen in $\mathrm{N}+\mathrm{N}_{3}$ chemiluminescence spectra, ${ }^{7}$ but their transition probabilities are significantly smaller than those of the $\mathrm{B} \rightarrow \mathrm{A}$ bands. ${ }^{13}$ The $\mathrm{W}^{3} \Delta_{\mathrm{u}}$

(1) Illenberger, E.; Comita, P. B.; Brauman, J. I.; Fenzlaff, H.-P.; Heni, M.; Heinrich, N.; Koch, W.; Frenking, G. Ber. Bunsenges. Phys. Chem. 1985, $89,1026-1031$.

(2) Clark, T. C. Clyne, M. A. A. Trans. Faraday Soc. 1970, 66, 877-885.

(3) Pritt, A. T., Jr.; Coombe, R. D. Int. J. Chem. Kinet. 1980, 12, 741-753.

(4) Pritt, A. T., Jr.; Patel, D.; Coombe, R. D. Int. J. Chem. Kinet. 1984, 16, $977-993$.

(5) Habdas, J.; Wategaonkar, S.; Setser, D. W. J. Phys. Chem. 1987, 91, $451-458$.

(6) Yamasaki, K.; Fueno, T.; Kajimoto, O. Chem. Phys. Lett. 1983, 94, $425-429$.

(7) David, S. J.; Coombe, R. D. J. Phys. Chem. 1985, 89, 5206-5212.

(8) David, S. J.; Coombe, R. D. J. Phys. Chem. 1986, 90, 3260-3263.

(9) Marinelli, W. J. Private communication.

(10) Henshaw, T. L.; MacDonald, M. A.; Stedman, D. H.; Coombe, R. D. J. Phys. Chem. 1987, $91,2838-2842$.

(11) Henshaw, T. L.; McElwee, D.; Stedman, D. H.; Coombe, R. D. J. Phys. Chem. 1988, 92, 4605-4610.

(12) Lofthus, A.; Krupenie, P. H. J. Phys. Chem. Ref. Data 1977, 6, 113-307. 